\title{
CUANDO LAS ALMAS NO PUEDEN SER CUSTODIADAS: EL FUNDAMENTO IDENTITARIO EN LA COLONIZACIÓN ESPAÑOLA DE GUINEA ECUATORIAL
}

\author{
JACINT CREUS \\ Universidad de Barcelona
}

RESUMEN: En 1777, la monarquía española obtuvo de Portugal las islas de Fernando Poo, Corisco y Annobón "y el territorio continental adyacente». Por primera vez desde el Tratado de Tordesillas de 1494, se reconocía a España el derecho a la posesión de territorios propios en el África sudsahariana. La realidad, sin embargo, fue atrayéndolos a la órbita ultramarina británica, a medida que el comercio esclavista se fue convirtiendo en "trata legal» de otros productos. Sólo la tardía incorporación de España al sistema colonial contemporáneo supuso la paulatina conversión de Guinea en una "colonia de producción» impulsada ideológica y económicamente por los misioneros claretianos. En las colonias españolas, los africanos debian "conseguir» una nueva identidad cultural, como un reto civilizatorio planteado y ofrecido a quienes eran concebidos como carentes de identidad cualquiera. Este artículo pretende describir los principios ideológicos y los mecanismos prácticos utilizados por lo misioneros para conseguir imponer en Africa un sueño que en Europa se les escapaba; principios y mecanismos heredados de su experiencia europea y de los propósitos eclesiales puestos en marcha, a lo largo del siglo XIX, en el viejo continente.

Palabras Clave: Historia de África. Guinea Ecuatorial. Misiones. Aculturación.

ABSTRACT: In 1777 the Spanish monarchy obtained from Portugal the islands of Fernando Poo, Corisco and Annobón "and adjacent continental territory». For the first time since the Treaty of Tordesillas in 1494, the right of Spain to bold territories of its own in south-Saharan Africa was recognised. The reality, however, was attracting them to the British overseas sphere of influence as the sale of slaves was gradually replaced by the «legal trade». Only the late entry of Spain into the contemporary colonial system brought with it the gradual conversion of Guinea into a "productive colony", promoted ideologically and economically by the Claretian Missionaries. In Spanish colonies, African people had to "earn» a new identity, presented and offered as a civilizing challenge to those who were seen as lacking any identity 
whatsoever. This article attempts to describe the ideological principles and practical mechanisms used by the missionaries to impose in Africa a dream that in Europe was slipping out of their grasp, principles and mechanisms inherited from their European experience and from the ecclesiastical objectives set in motion, throughout the $19^{\text {th }}$ century, on the old continent.

KEY WORDS: African History. Ecuatorial Guinea. Missionary Activity. Acculturation.

Nec custodiri, ni uelit, ulla (mens) potest Ovidio, Publio: Amorvm, lib. III, 4, 6.

En 1777, la monarquía española obtuvo de Portugal las islas de Fernando Poo, Corisco y Annobón «y el territorio continental adyacente», a cambio de las posesiones, hoy brasileñas, de Santa Catalina. Por primera vez desde el Tratado de Tordesillas de 1494, se reconocía a España el derecho a la posesión de territorios propios en el África sudsahariana, con la intención explícita — por parte de nuestro país - de establecer en aquellas islas empresas esclavistas.

La realidad, sin embargo, dio la espalda a los presuntos intereses españoles. Teóricamente colonizadas, aquellas islas portuguesas no sólo estaban desiertas de europeos y de cualquier infraestructura comercial disponible para el vergonzoso comercio triangular, sino que la primera expedición oficial, organizada en 1778 desde Montevideo, resultó un desastre: hostilidad y resistencia por parte de los indígenas, fiebres palúdicas, escasez de alimentos, motines... ${ }^{1}$ Sólo veinticinco de los ciento cincuenta tripulantes iniciales regresaron a Sudamérica, y los territorios guineanos quedaron envueltos en un halo de peligrosidad.

La segunda expedición oficial española no llegaría a las islas hasta 1841, sesenta y tres años más tarde. Pero, mientras tanto, el contexto internacional había cambiado radicalmente: España veía cómo se iba disolviendo su antiguo sueño imperial; y en 1807 Gran Bretaña, la potencia militar, comercial y marítima de la época, había abolido aquel tráfico de esclavos para el que aquellas islas remotas parecían destinadas. Los tratados hispano-británicos contra el tráfico ilegal de personas (1817 y 1835) habían establecido el derecho de visita a los buques españoles por la Marina británica; y también determinados mecanismos de control, entre los cuales la creación de tribunales mixtos en Freetown y en Fernando Poo.

1 Argelejo, Conde de: Noticias, documentos y avisos: expedición de 1778, edición de Mariano L. de Castro, Vic, Ceiba, 1999, 93 págs.. En general, el conjunto de los libros publicados por Ceiba en su colección de «Documentos de la colonización» da una visión bastante amplia del tema de este artículo. También mi tesis de doctorado: Creus, Jacint: Action missionnaire en Guinée Équatoriale, 1858-1910: perplexités et naïvétés à l'aube de la colonisation, Lille, Presses Universitaires du Septentrion, 2002, 1049 págs. 
Paradojas de la Historia: unos territorios adquiridos para el comercio de esclavos, iban a empezar su etapa de colonización con el establecimiento de un tribunal para su represión. Es en esta lógica que británicos procedentes de Sierra Leona crearon la ciudad de Clarence - la futura Santa Isabel, la actual Malabo- en 1827. Y si bien ese tribunal nunca llegó a funcionar, aquellos colonos negros y mulatos, ciudadanos británicos, establecieron en Fernando Poo y en Corisco sus enclaves comerciales, cambiando la antigua trata ilegal por el llamado comercio legal de aceite de palma y otros productos menores. Las islas españolas pasaban a ser una pieza más del entramado ultramarino británico, y en ellas se empezaba a desarrollar una comunidad fernandina, de habla inglesa, religión protestante, vocación comercial y amplias relaciones en aquel tejido colonial, que sería enormemente influyente hasta la descolonización definitiva del país en 1968.

El éxito británico estimuló las ansias españolas, en un contexto ultramarino - el español - que a medida que avanzaba el siglo se fundía como el hielo. Un intento británico de compra de los territorios - acordada en 1840 con el Gobierno de Madrid por 60.000 libras esterlinas - provocó la respuesta airada de la prensa española y de las Cortes, que proclamaron la evidente españolidad de las islas. A partir de este momento, el Gobierno de Madrid organizó algunas expediciones oficiales a Fernando Poo, sin que ninguna empresa española se atreviera a competir con las ya establecidas en las islas. A partir de 1858, año en que empezó la efectiva colonización española, se planteó un tipo de intervención mínima y estatal: el Gobierno de Madrid mantendría en Santa Isabel a un oficial de Marina como gobernador, el cual contaría con una pequeña dotación militar y la ayuda civilizadora de una limitada comunidad jesuita. El comercio permanecería en manos británicas.

Los vaivenes de aquel modelo mínimo vivieron un momento álgido durante la primera República, que minimizó más si cabe la presencia española en Guinea. Reducida a una expresión casi testimonial, no fue hasta los albores de la conferencia de Berlín, concretamente en diciembre de 1883, cuando el Estado, aunque bajo el mismo esquema, aumentó considerablemente su presencia oficial en la colonia.

En esta nueva etapa, que sería la definitiva en el proceso de colonización, los misioneros claretianos serían la punta de lanza de un Gobierno que les financiaría y les permitiría todo: a cambio de su extensión por todos los territorios coloniales, indispensable para el reconocimiento internacional de la colonia, mantendrían un oscuro monopolio en el ámbito educativo, propio del Antiguo Régimen, que les permitiría una situación privilegiada y una actuación directa sobre los indígenas (bubis en Fernando Poo, ndowé y fang en el continente y en el estuario del Muni, ambú en Annobón).

Y es que el propio concepto de colonización había cambiado. Si la etapa británica se caracterizó por una trata comercial que no precisaba apenas la ocupación del territorio y sólo la complicidad de sus habitantes, la pretensión española era convertir aquellos territorios en una colonia de producción de determinados productos, entre los cuales el cacao sería el rey. Convertir Fernando Poo en 
una finca fue el objetivo proclamado por misioneros y administradores coloniales; un objetivo que requería, a su vez, la conversión de los indígenas en trabajadores útiles al nuevo sistema económico.

La acción educativa, por lo tanto, era la pieza maestra del nuevo modelo. Los claretianos, al aplicarla, fueron - lógicamente- esclavos de unos sueños, unas ideas y unas contradicciones que viajaron con ellos desde España. Al darles forma en África, quisieron incorporar a los guineanos a esos mismos sueños, ideas y contradicciones, como si aquellas sociedades no fueran más que un vaso vacío que hubiera que llenar con un contenido al gusto. $\mathrm{Y}$ así fue como crearon un grave conflicto en el seno de esas sociedades a las que pretendían servir - las africanasque también poseían sus propios sueños, ideas y contradicciones. Un conflicto que fue colectivo, pero que los misioneros introdujeron de forma individual. Un conflicto que este artículo pretende analizar sin dejar de lado a sus actores más olvidados, los guineanos, obligados a dejar de ser para poder ser tenidos en cuenta.

\section{QUE TUS OJOS APRENDAN A LLORAR CUANDO LO DESEES QUIN ETIAM DISCANT OCULI LACRIMARE COACTI ${ }^{2}$}

El chisme desabrido, repetido como un ritornello en buchinches de todo el continente, se me hace explícito en una lectura reciente: «Era en muchos aspectos un ejemplar característico del tipo de blancos que llegaban entonces al Congo: un joven soltero necesitado de trabajo, ansioso de aventuras y con algún problema en su pasado» ${ }^{3}$. Al aprestarme a escribir otra vez sobre la peripecia claretiana en Guinea Ecuatorial, tengo presente hasta qué punto aquel episodio inacabado mudó conductas, sentimientos y valores en parajes amados que los misioneros quisieron convertir en "país», en «afrohispánico» y en «moderno». Hace ya mucho tiempo que la interpretación de proezas evangélicas se puebla de pensamientos confutadores («Turpe senex miles, turpe senilis amor», proclama el poeta exiliado). Y si la lingüística etimológica ironiza mordaz sobre la denominación de aquellos «esclavos de Dios» que tan poco pedían para sí mismos («sibi pauca rogent» $)^{4}$, el sonsonete tabernario establece otra verdad de runrún: que las almas no pueden ser custodiadas.

2 Ovidio, Publio: op. cit., liber I, 8, 83. Los títulos de todos los apartados pertenecen a la misma obra.

3 HochsCHILD, Adam, El fantasma del rey Leopoldo, Barcelona, 2002, p. 215-216.

$4 \mathrm{Si}$ interpretamos que la palabra «misionero» deriva del verbo latino MIITTĚRE, la emparentamos con significaciones tales como «cometer», «comisario», «acometer», «dimitir», «entrometerse», «entremés», «intermitencia», «intromisión», «omisión», «malmeter», «prometer», «comprometer», «remitir», «remesa», «someter», etc. Si reducimos el campo semántico a partir del participio MǏssus, aparecerán «mensaje» y todos sus derivados, con acepciones tales como «enviado», «criado» o«dinero»; y otras voces, términos y sentidos, como la propia «misa», «tiro», «clemencia», «reconocimiento» o «licencia». Se trata de una lista elocuente, escueta, sesgada y parcial, correspondiendo al lector cualquier decisión sobre la procedencia — nunca mejor dicho— de cada vocablo. 
Tomamos por primera vez a nuestros hijos en brazos, y comprendemos que no podemos pedir más. No más en la tierra. No más para nosotros. No más para los nuestros. Nada más intenso, nada más profundo, nada más rabiosamente agudo. Nada superior. Sicarios vehementes de «la única» religión verdadera, deshonrada por la ceguera del fanatismo, los intérpretes umbrosos de esta historia renunciaban a experimentar la emoción humana más grande, el más penetrante de los desasosiegos. La agitación turbadora de los hábitos venerables, los vestidos talares, las luengas barbas, los cuerpos impolutos, el tiempo generoso, se gestaba en una anomalía profanadora: sublimar la negación de sí mismos en la exaltación que exigían a otros. Y esa exigencia desnaturalizada era el problema de su pasado que había llevado a esos jóvenes solteros a una cierta África a la que habían llegado ansiosos de aventuras henchidas de almas a las que custodiar: para que esas almas blancas de negritos buenos no se perdieran en el estercolero de la modernidad. Para ello, insolente pericia, aplicaban el primer principio de la modernidad misma: Los padres tomamos a nuestros hijos en brazos. Desbordado el afecto, nuestra inquietud suprema estriba en que adquieran una educación en la que intervendremos poco. Ni nos sentimos ni nos reputan capaces para acometer lo que realizaron nuestros antecesores desde siempre. Luengas barbas, cabezas sesudas, profesores «de carrera» orientarán a nuestros retoños fuera de nuestras vidas. Estarán dentro si consiguen llegar fuera. Nuestro éxito gravitará en su ausencia.

Volvamos al preludio: El control de la educación de los hijos, perdido por los padres en Europa, cambiaba de escenario y en esa cierta África pasaba a llamarse «civilización» sin ningún reparo. Pobres padres ignorantes de Europa, pobres padres salvajes de Africa. Unos y otros aprenderían su derecho a no abandonarse a la ira, a no macerar en lágrimas el corazón compungido, a exorcizar con su bendición apenas contrita una separación doliente que encubría su propia desarticulación. Nunca más en la tierra. Nunca más para nosotros. Nunca más para los nuestros. La custodia de las almas de los negros tuvo su introito en la custodia de las almas de los blancos. Unos y otros acechados por quienes, haciéndose llamar Padres, presumían de tener el mismo sexo que los ángeles. Padres helióticos, Padres ambiguos, a la vez protectores distinguidos de estructuras obsoletas — patriarcales! - y exponentes devotos de esa nueva modernidad que no precisa hijos arropados con un beso.

Una conjunción que promete seguridad, estabilidad y amparo a sus beneficiarios:

La campana: scandisce i ritmi della vita all'interno della missione ma si sente di lontano, invade lo spazio e — con lo stabilizzarsi della presenza missionaria - prende a comunicare segnali di volta in volta più intrusivi: la scadenza liturgica, ma anche l'avvistamento di un animale feroce, di un nugolo di cavallette, l'avvicinarsi di una tempesta. Il tempo della campana si impone sul tempo dell'»interno» africano, cadenzato su una precisa utilizzazione e simbologia dello spazio5.

5 Nanni, Stefania, Lo spostamento dei confini: lo spazio missionario nell'Africa Occidentale, en BOeSCH, Sofia \& SCARAFFIA, Lucetta: Luoghi sacri e spazi della santità, Turín, 1990, p. 173. 
Promesas, aquéllas, que al parecer requieren promotores expuestos al riesgo, a la amenaza:

Andaban [dos misioneros] bien descuidados, conversando, cuando, de repente, ven pasar sobre sus cabezas una lluvia de dardos o lanzas de madera llamados por los bubis mochika, capaces cada uno de ellos de causar la muerte. Al principio, como no veían a nadie, no sabían lo que era aquello; pero, entendiendo luego el peligro en que estaban, retrocedieron a toda prisa sin que les hubiese alcanzado ninguna. No pudieron saber quiénes habían sido los que se ocultaban en aquella emboscada; pero fue un aviso serio para no alejarse de casa sino bien acompañados ${ }^{6}$.

¿El peligro, disimulado en el bosque, ejercido con pérfida felonía, desafiado por el arrojo misionero, peldaño previo a la paz de la campana envolvente? Sólo en las Historias misioneras el bien substituye al mal de forma inexorable. La realidad es un bucle de logros y desazones para todos los figurantes. Pero la mirada religiosa la anamorfizaba con simpleza: Para que esa campana trascendiera los confines de la Misión, saliera al exterior y se convirtiera en referente acústico obligado, territorial y simbólico de la vida cotidiana, la estrategia indicada no era la integración; sino, nuevamente, la separación. No se trataba de que nadie lanzara dardos venenosos contra los admirables titanes patrocinadores del bien común; se trataba de conseguir que la perfidia incontrolada no se abandonase a la ira, que no macerase en lágrimas el corazón compungido, que exorcizase con una bendición apenas contrita su propia desarticulación. Cualquier Dios es selectivo.

\section{Tu BELLEZA YA NO CAUTIVA Mis OJOS NEC FACIES OCULOS IAM CAPIT ISTA MEOS}

El 8 de junio de 1884 — casi medio año después de la llegada a Santa Isabel de la primera expedición claretiana ${ }^{7}$, casi medio año antes del inicio de la conferencia de Berlín ${ }^{8}$ - el poeta Jacint Verdaguer alcanzaba París por primera vez en su dilatada experiencia de viajero, iniciada en el Ultramar antillano. La ciudad vertiginosa se estremecía, venerada ya como vértice y cúspide de una mo-

6 Coll, Ermengol: Misión de María Cristina, edición de Jacint Creus, Vic, 1995 [circa 1900], p. 23-24. El P. Coll fue el tercer Superior de las Misiones claretianas en Guinea, primero como Prefecto Apostólico y después como Vicario Apostólico de Fernando Poo, el primero nombrado por el Vaticano para aquellos territorios españoles.

7 Formada por 6 Padres y 6 Hermanos, un número aparentemente muy crecido para una ciudad de apenas un millar de habitantes y mayoritariamente protestante, aquella primera expedición salió de Barcelona el 5 de octubre de 1883 y desembarcó en Santa Isabel el 13 de noviembre del mismo año, al grito de iViva Fernando Poo! de su prefecto y superior, P. Ciriaco Ramírez, antiguo párroco de Codornices (Segovia) y único no catalán del grupo.

8 La conferencia de Berlín tuvo lugar entre el 25 de noviembre de 1884 y el 26 de febrero de 1885. 
dernidad presentida que, entre muchos otros, iría incorporando a su vitalidad exuberante elementos y particularidades del llamado arte primitivo. África sería presa de pruritos variopintos, camelo de raptores de naturaleza dispar. De momento, nuestro poeta más excelso participaba en una procesión que las Hijas de María culminarían en el lugar preciso de la loma de Montmartre en que hoy se hunde la cripta del templo del Sacré-cœur: «Dieu de clémence, / Dieu protecteur, / sauvez, sauvez la France / au nom du Sacré-cœur»`. Místico arrebatado, Verdaguer concibió la capital de la luz como «la Babilònia de l'Apocalipsi», e intuyó de forma magistral el sentido que debía tener su fe en aquel universo de liviandad desordenada:

Jo em figurava veure l'Església de França captiva i encadenada a les catacumbes, aixecant sos ulls a l'escassa llum que entra per aquells finestrals bizantins, i plorant, plorant sa llibertat perduda, son Déu tret ignominiosament de les escoles, dels llibres i de l'ànima de la novella generació; plorant sos amadíssims religiosos llençats de llur mística cel-la, les germanes de la Caritat tretes del peu del malalt, que mor sense un consol $i$ una esperança; la indiferència del vell, la llicència del jove i l'escàndol dels petits, aquests àngels de la terra a qui no es deixa aixecar los ulls al cel, que s'emmiralla en sos ulls i en ses ànimes pures.

Una prosa tejida con brillantez —evocación transmutada en invocación-, que describe un sentimiento de "persecución» ampliamente compartido por el pueblo católico europeo del siglo XIX, estimulado desde todos los púlpitos y actualizado en cada una de las manifestaciones de laicidad abanderadas por aquella Tercera República que profesaba su fe en la separación de poderes. Cada una de estas muestras podía ser percibida como una «agresión», ante la cual la jerarquía eclesial y los fieles levantaban toda suerte de símbolos de resistencia, como el propio Sacré-cœur. La prosa del poeta garantizaba seguridad, estabilidad y amparo a los creyentes del presente, proyectando hacia el futuro lo que debía llegar de forma inexorable:

Un dia, que no sabem si és lluny o a prop, la París revolucionària, desvetllant-se al so de campanes mai sentides, obrirà els ulls i veurà en sa muntanya més alta una basílica major que totes ses basíliques; més alta que el Panteó i l'església dels Invàlids; més que el superb edifici de l'Ôpera i l'Hôtel de Ville; un campanar més alt que el monòlit egipci de la plaça de la Concòrdia; més que la columna de Vendôme; un edifici més alt que tots sos edificis, i al bell cim la creu, que dominarà la París antiga i la moderna, la ciutat i els afores, les cases, els boscos, els camps i les muntanyes; i aixecant al cel sos braços, rosats amb la sang d'un Déu, demanarà perdó per la ciutat culpable.

9 Verdaguer, Jacint: Excursions y Viatges, Barcelona, s/a. El relato del viaje a París ocupa las páginas 147-163. El episodio de Montmartre se encuentra en las páginas 155-161. En todos los fragmentos transcritos se ha modernizado la ortografía. 
La «ciudad culpable», pues, como oposición a «la ciudad dominada por la campana». Es el paradigma ideológico establecido por la Iglesia decimonónica, angustiada por su pérdida de poder, por el derrumbe de sus valores, por la escasez de su influencia en la vida cotidiana del hombre moderno. Verdaguer hace suya la respuesta de la Iglesia francesa: «un edificio más alto que todos sus edificios». El poder de la apropiación de la modernidad, izado contra el valor de la modernidad. Frente al «espacio agresor» que lo ocupa todo, un «espacio redentor» notorio, aunque cercado y angosto, capaz de proteger a las Hijas de María, al pueblo fiel, de las tentaciones «del mundo». Frente a ese «mundo», la Iglesia intentará construir «su mundo», creando toda suerte de espacios «regulados por el sonido de la campana», espacios más «modernos» que el Panteón, los Inválidos, la Ópera o el Hôtel de Ville, en que impere esa cruz que «levantará al cielo sus brazos, enrojecidos con la sangre de un Dios, pidiendo perdón por la ciudad culpable». Espacios fuera del tiempo y del espacio, ejemplos de modernidad a la vez que vestigios de una época fundacional encarnada en la fanfarria procesional:

No sabia adonar-me d'allò que veien mos ulls; aquella gent que sortia de sota terra, orant i cantant, em feia l'efecte de gent d'altre país i d'altra època; dels màrtirs companys de Sant Dionís, que sortissin de llurs sepulcres; dels fills de Clovis, de Carlemany i de Sant Lluís, que obrint llurs parpelles a l'enderrocament del santuari, trenquessin les lloses de llurs tombes i vinguessin a acabar en eixa França desventurada l'obra salvadora que hi començaren; i a encendre-hi de nou la flama de l'amor a Jesucrist, que s'hi apaga10.

Espacios, pues, «dominadores del París antiguo y del moderno».

Algunos de esos «espacios redentores» llevaron el sello de la intervención celeste libre de intermediarios: fenómenos de religiosidad popular como el de las Verges trobades darían paso a fenómenos de religiosidad popular como el de las apariciones de la Virgen, manifiestamente ubicua en la segunda mitad del siglo, también en esa cierta África. Tiempos de persecución, sin embargo, son también tiempos de exaltación; y, sobre todo, tiempos de compromiso: la multiplicación de vocaciones, de iniciativas, de órdenes y congregaciones nuevas, de jóvenes solteros ávidos de aventuras religiosas, impregnará el ambiente religioso de un espíritu misionero que encontrará terreno abonado en el «espacio agresor» europeo así como en las tierras africanas, «nuevas» sin duda para los no africanos, pobladas de cafres de brutalidad irrefrenable, ocultos tras cualquier emboscada, proclives —además! - a suministrar las palmas del martirio.

La creación de «espacios propios» asociados a la idea de «modernidad», sin embargo, no se redujo a la construcción de templos expiatorios desmedidos como el colosal de la cima de París; o la Sagrada Familia y el Tibidabo de Barcelona, a la cabeza ambos de obsesiones y obcecaciones visitantes. Los derechos

10 Op. cit., p. 158. 
individuales, conquistados en Europa con mucha más sangre que la de un Dios, establecían una barrera penosamente franqueable ante «la indiferencia de los ancianos y la vida licenciosa de los jóvenes». Unos y otros podían apartarse de la Iglesia sin que les alcanzase castigo alguno, salvo en ese avernal dantesco recreado al detalle por los más célebres predicadores. Quedaba por chalanear ese «escándalo de los niños, ángeles de la tierra a quienes no se permite levantar los ojos al cielo, que se refleja en sus pupilas y en sus almas puras». Unos niños a los que la sociedad «moderna» debía «educar», proclamada ya la clamorosa ignorancia de unos padres desconcertados por tantos avances. Los intermediarios de Dios conjugarían dos polos discrepantes que, juntos, actuarían como un nuevo imán que aprisionaría, custodiándalas, las almas de aquellos ángeles de la tierra.

Surgieron, pues, los internados, santuarios de modernidad a la vez que vestigios de una época fundacional. Y esa obsesión clerical por controlar un mundo escolar empapado de virtudes. La disciplina rigurosa, el alejamiento de las familias, el conocimiento moderno como paradigmas de un ascenso social que raramente se producía. En Europa, la rendición de los padres ante tanta calidad de educación, aparentemente inasequible en el medio familiar, fue rápida: lasallianos, concepcionistas, vedrunas, claretianos, escolapios, salesianos, maristas y una estirada pléyade de Instituciones educativas, prometían seguridad, estabilidad y amparo a sus beneficiarios y dejaban constancia de una nueva paradoja. «Si només els rics estudien, només els rics sabran»: son palabras que Raimon ponía en labios de un obrero represaliado en $1963^{11}$. Se mantiene, pues, el artificio: la educación es arma de resistencia popular para evitar, siguiendo la misma canción, «que ens enganyin amb qualsevol cosa»; y, al mismo tiempo, se presenta como algo «externo», ajeno a la cultura del propio grupo. Sólo los «radicales» se oponen al sistema escolar universalizador:

Bisogna chiudere le scuole - tutte le scuole. Dalla prima all'ultima. Asili e giardini d'infanzia; collegi e convitti; scuole primarie e secundarie; ginnasi e licei; scuole techniche e istituti tecnici; università e accademie; scuole di commercio e scuole di guerra; istituti superiori e scuole d'applicazione; politecnici e magisteri. Dappertutto dove un uomo pretenda d'insegnare ad altri uomini bisogna chiudere bottega. Non bisogna dare retta ai genitori in imbarazzo né ai professori disoccupati né ai librai in fallimento. Tutto s'accomoderà e si quietarà col tempo. Si troverà il modo di sapere (e di sapere meglio e in meno tempo) senza bisogno di sacrificare i più begli anni della vita sulle panche delle semiprigioni governative $^{12}$.

La Iglesia fue más eficaz: se aprestó a custodiar las almas puras de los niños comprometiéndose a convertirlos en ciudadanos, en privilegiados.

11 No el coneixia de res, 1978.

12 PAPINI, Giovanni: Chiudiamo le scuole!, Milán, 1996 [1914], p. 61. 


\section{LA VISIÓN QUE AMEDRENTÓ MI ESPÍRITU}

TERRUERUNT ANIMUM TALIA UISA MEUM

El 18 de junio de 1884 — poco más de medio año después de la llegada a Santa Isabel de la primera expedición claretiana, cinco meses antes del inicio de la conferencia de Berlín, 10 días después de que el poeta Jacint Verdaguer augurara el piadoso futuro de París, rendido al Sagrado Corazón de Montmartre- el P. Josep Xifré, Superior General de la congregación claretiana, rendía visita al P. Ciriaco Ramírez, Superior de la Misión de Santa Isabel de Fernando Poo. Tiempos difíciles y transportes cicateros, para viajar al África Ecuatorial de entonces. Cronología frenética, desde la aparición de los claretianos en su nueva Misión africana: en noviembre de 1883 habían llegado a la colonia española como Misión de Estado, heredando en ella una iglesia y una Casa abandonada once años atrás por los jesuitas que les fue entregada en enero. En diciembre, el P. Ramírez había visitado la bahía de San Carlos (la actual $L u b a$ ). En enero, Libreville y Corisco. En febrero, aquellos ascéticos intrépidos habían obtenido la publicación de un decreto declarando la obligatoriedad de realizar la enseñanza en español, contra la escuela anabaptista de la ciudad, de expresión inglesa. En marzo habían convertido la Casa de Santa Isabel en un pequeño internado y requerían al gobernador general el monopolio de la actividad educativa en la capital, contra la existencia de una pequeña escuela estatal ocupada - literalmente- por los claretianos en abril. En mayo se solucionaba el problema de la enseñanza en su favor, de forma provisional $\mathrm{Y}$ en junio llegaba aquella reunión inesperada. ¿Una auténtica carrera enloquecida por parajes aún desconocidos?

No del todo: Santa Isabel y San Carlos, en la isla de Fernando Poo; y Corisco, frente al estuario del Muni, eran las únicas sedes de los numerosos negocios europeos de la colonia, la mayoría no españoles, en aquella época de factorías ribereñas. Libreville, una de las llamadas «ciudades de libertad», como Santa Isabel, porque en ellas desembarcaban a los esclavos liberados de los negreros ilegales, presumía además de la Misión católica más antigua de la zona (Sainte Marie, fundada en 1844 por el espiritano Monseñor Bessieux). La conversión de la Misión fernandino-isabelina en un internado y la exigencia del monopolio educativo representaban dos asuntos innegociables, un tour de force que no admitía réplica y que provocó el rápido desplazamiento de Josep Xifré a aquella Guinea tan distante: si el Estado quería ver satisfechos sus deseos de que en el conjunto del territorio colonial hubiera una presencia española demostrable, es decir si quería participar en el pasteleo de Berlín, los misioneros se lo garantizaban por poco dinero; a cambio, según parece, de universalizar en la colonia el modelo eclesiástico de intervención.

¿Una colonia moderna que sólo costaría que la Iglesia asumiera funciones estatales? Ambos poderes podían exhibir, para ello, una coartada magnífica: la «civilización» de los «negritos»; niños a los que el sistema colonial «moderno» debía «educar», una vez determinada la clamorosa ignorancia de unos padres tildados de «salvajes desalmados» por unos y otros. Los intermediarios de Dios 
conjugarían de nuevo dos polos discrepantes que, juntos, actuarían como un nuevo imán que aprisionaría, custodiándalas, las almas de aquellos angelitos de esa tierra yerma de cultura donde los blancos se disponían a inaugurar la Historia. Claro que la rendición de los padres africanos ante tanta calidad de educación, inasequible sin duda en el medio familiar y evidentemente exterior al grupo, estaba por ver. Aun así, sólo los «radicales» podían oponerse a un sistema escolar universalizador que convertiría a sus usuarios en civilizados primero, en ciudadanos después, en privilegiados siempre. ¿Se puede ser más visionario? Si cada cual es esclavo de sus propias imágenes y de sus proyecciones peculiares, en el retintín de las levíticas soñarreras sacerdotales aquellos angelitos negros aparecían «separados» de la depravación libertina de la modernidad consentidora y del provecto arcaísmo de un continente fosilizado y disoluto.

De ahí el afán del P. Ramírez por asegurar, en las centelleantes visitas de su primer apostolado, el acuerdo in pectore de las autoridades africanas con sus sueños europeos, apergaminados y ultramontanos, reversionistas, factibles quizás en tierras remotas:

Después de instalada en Santa Isabel la Misión y organizado su funcionamiento, el Rdmo. Padre Ciriaco Ramírez se dedicó a explorar el campo que se le había confiado. Por lo cual, después de haberse hecho cargo del estado de los bubis de Banapá y Basilé, alargó sus excursiones hasta San Carlos, lo cual fue relativamente fácil con el apoyo y medios que le prestó el hacendado Guillermo Vivour, que con su trato con los bubis de aquella región había obtenido un perfecto conocimiento de los lugares donde habitaban y de su modo de vivir. Acompañó, pues, Vivour al Rdmo. Padre, en una de sus excursiones, a una ranchería bubi en donde le llamó la atención el que, habiendo ido a buscar agua con una descomunal calabaza, después le presentaran un vaso de cristal. Convidó a los indígenas a besar su crucifijo; pero ellos se resistieron, creyendo que era un ascua de fuego. Preguntóles si gustarían tener a los misioneros entre ellos, y contestaron que sí13.

«Explorar el campo que se le había confiado» equivalía, pues, a establecer supuestos acuerdos de principio - a los que los misioneros concedían confianza y eficacia jurídica - con unos africanos que, en tal tesitura, parecían - pese a supercherías inevitables— «razonables», «buena gente simplona». Incluso, en los casos en que su autoridad era grande, la literatura misionera los puede presentar como "poderosos reyes» proclives a la tarea evangelizadora: como en el caso del P. Joaquim Juanola, primero en visitar al «invisible» «rey» Moka:

Sólo diré que el gran Moca se mostró muy caballero en todo, y amigo del Gobierno, y más de los Padres, en quienes depositaba toda su confianza una vez establecidos en estos sus dominios, que sabía él no tardaríamos ${ }^{14}$.

13 Coll, Ermengol: op. cit., p. 13-14.

14 JuANOLA Joaquim: Una excursión a los pueblos bubis: Archivo General de los Misioneros Claretianos (AG.CMF), Sección F, Serie N, Caja 16, Carpeta 1. Documento inédito de 8 de enero de 1888. 
Sorprende la autoridad administrativa atribuida por los misioneros al «rey de los bubis», y ese trato deferente del religioso hacia el «buen salvaje», que sólo demuestran a sus huéspedes las personas de buena educación. Un trato que en posteriores encuentros se tornaría arisco y brutal:

Por su parte el Sr. Cheli, comandante del barco, supo muy bien jugar el papel. A las puertas mismas de Moka estuvimos, yo por tercera vez, y como él [Moka] estuviese quejoso porque los niños y aún niñas iban a la Misión, el Sr. comandante le leyó la cartilla y le dijo: «Él dice que si los niños y niñas van a la Misión, luego uno quiere a otra y el Padre los casa y pierdes». «Esto» — le respondió«es lo que debe ser, y cuidado con molestar a la Misión; si no, estas armas que traigo para defenderte y que te respeten todos los bubis serán para castigarte». Lo que no le gustaba mucho, pero tuvo que callarse. Y así se hizo en todas partes: respeto al Gobierno y a la Misión. iOjalá se hiciera esto con frecuencia! iCuánto ganarían la Religión y la Patria! Si no, no hay quien los saque de los bosques. iSi al menos dejaran venir libres a los niños y niñas!!! Pero no hay medio... ${ }^{15}$.

Seguramente el pobre rey Moka no comprendía la Historia colonial, ni por qué aquel sujeto de luengas barbas y cabeza sesuda pasaba de llamarle «caballero» a aplaudir que gente áspera y armada «le leyera la cartilla». La exigencia desnaturalizada de niños y niñas para la Misión daba respuesta al problema de su pasado que había llevado a esos jóvenes solteros a una cierta África a la que habían llegado ansiosos de aventuras henchidas de almas a las que custodiar: para que esas almas blancas de negritos buenos no se perdieran en el estercolero de la modernidad europea ni en el de la brutalidad de sus negras familias. En el África Ecuatorial, pues, el triunfo de la fe, el dominio de la cruz sobre las casas y los bosques, los campos y las montañas, planteaba un problema de presente a personajes que, como el rey Moka, no parecían dispuestos a renunciar a la mayor de las emociones humanas, ni a apoyar con su bendición apenas contrita una separación doliente que encubría su propia desarticulación. Prefería que nadie «los sacara de los bosques», y su determinación era suficientemente clara como para que un arrabalero furioso blandiera ante él armas amedrentadoras que podían castigarle.

La mutación que señalaría el rumbo de la colonia se gestó en aquella reunión aciaga de junio de 1884, mantenida por dos claretianos exultantes: el Superior General y el Superior de Santa Isabel se habían cruzado en pleno Atlántico, en barcos distintos, en sentidos opuestos, en súbitos viajes improvisados por un alborozo desbordante; y por fin se encontraban, ya en Santa Isabel, depositario cada uno de ellos de una llave maestra en el infierno de la sotana. El Superior General había movido sus resortes en Madrid, despejando el futuro del sistema escolar guineano en ciernes: el monopolio de la educación sería posible en Guinea, en Guinea

15 Carta del P. Joaquim JuAnola, secretario de la Misión de Santa Isabel, al P. José Mata, procurador de las Misiones claretianas ante el Gobierno de Madrid. AG.CMF, F, N, 8, 8. 
entera, según las disposiciones legales que se le habían prometido. El Superior de Santa Isabel, santo varón «dotado de espíritu robusto, mortificado en extremo y de natural de suyo colérico y arrebatado» ${ }^{16}$, había acudido a la vieja Sainte Marie, palpando con sus propios ojos, hecha realidad, la visión quimérica de toda la cristiandad acosada; y presentaba al primado de su orden un convencimiento terminante: la educación de los hijos de los salvajes era posible en Guinea... mediante la separación, el alejamiento y la disciplina. La educación y su monopolio. Llegar hasta Africa para encontrar Europa es un ejercicio poco excepcional, incluso en nuestros días. Un siglo y cuarto atrás, en un antiguo caserón jesuita, dos sacerdotes veteranos se conmovían al entrever la futura Iglesia triunfante en esos «espacios redentores» que se aprestaban a crear frente a los «espacios agresores» que acechaban en cada rincón de aquel paraíso perdido. El Dios de los blancos había elegido.

Mgr. Le Berre había substituido al fundador Mgr. Bessieux al frente del Vicariato Apostólico de las Dos Guineas en 1877. Poco después, cinco años antes de acoger fraternalmente al osado P. Ramírez, aparecido en el puerto de Libreville en un vapor inglés, rodeado de protestantes y con una calentura extrema, había descrito, en preceptiva carta a la Sagrada Congregación de Propaganda Fide ${ }^{17}$, el estado de la Misión heredada: un escrito extenso, que nos presenta un Vicariato en plena reestructuración y con una sede poderosa en Sainte Marie: en aquellos momentos se encontraban abandonadas las antiguas Misiones de Saint Joseph (frente a Corisco), Saint Thomas (Denis) y Saint Jacques (en el río Rhembone), que más tarde reiniciarían su actividad; mientras que, en la zona de Libreville, aparte de la Misión central se había fundado una en dirección al Muni, otra al sur de la actual ciudad, y una tercera en la ribera opuesta del río Pongwe. Una especie de tejido que impediría la expansión de la Misión claretiana hacia el sur e inflamaría las relaciones entre ambas comunidades evangelizadoras, educadoras y patrióticas. Pero en enero de 1884 el P. Ramírez no podía soñar todavía con esa expansión ni deslindar sus restricciones; sino comprobar que, para esa telaraña incipiente, los Padres franceses necesitaban ocupar a 12 sacerdotes, 8 coadjutores y 10 monjas de la Inmaculada Concepción de Castres, además de algunos catequistas y maestros auxiliares «indígenas». Mucho más que sus huestes isabelinas.

El propio Le Berre, en la carta aludida, destacaba, de todo ese conjunto, urdido en cuatro décadas de actividad, la solidez y la madurez adquiridas por la parroquia de Sainte Marie: un gran establecimiento, dotado de una iglesia muy amplia y varios edificios anejos, todos ellos de piedra:

C'est la Mission elle-même qui a construit ces bâtiments, petit à petit, par les mains des Frères et des néophytes indigènes: nous avions du reste le précieux avantage de posséder tous les matériaux sur le terrain même de la Mission.

16 Evangelizadores de la Guinea Española, Barcelona, 1948, p. 1-2.

17 Carta sin fecha [circa 1878]. Archivo de la Sagrada Congregación de Propaganda Fide (ASCPF), Scritture riferite nei Congressi: Africa: Angola, Congo, Senegal, Isole dell'Oceano Atlantico, vol. 8, f. 579-583. 
L'établissement des religieuses, distant d'un kilomètre et demi de Ste. Marie, et placé auprès du poste français, a été aussi construit par la Mission.

Y resumía con brevedad y concisión el trabajo llevado a término:

Nous avons à Ste. Marie, en fait des principales œuvres, l'éducation de la jeunesse, comprenant l'école primaire et secondaire et une école professionnelle où l'on forme les plus grands aux métiers les mieux adaptés aux besoins de ce pays. Les nombre de nos élèves entretenus aux frais de la Mission est ordinairement de 250.

La tarea «civilizadora» de los espiritanos se cerraba con el mantenimiento de dos hospitales para «indígenas», con unos cincuenta enfermos «qui nous offrent le moyen d'envoyer au ciel un grand nombre d'âmes» ${ }^{18}$. La actividad pastoral de los misioneros franceses, que recibían de su Gobierno laico y republicano 6.000 francos anuales, que mantenían una finca para su autoabastecimiento, y que empezaban a recibir importantes oleadas de inmigración fang, se resumía en unos 200 bautizos anuales; y encontraba su mayor obstáculo en

la polygamie qui règne dans toutes ces parties de l'Afrique. La plus grande occasion de chute ou d'infidélité pour nos pauvres néophytes, c'est le scandale donné par les Européens, commerçants ou autres, qui fréquentent ces côtes.

El «espacio agresor» es «todo lo que rodea = acosa» al «espacio redentor». Pero en Sainte Marie de Libreville ese «espacio redentor» existía y funcionaba con resultados notables. El P. Isidre Vila, en 1886, confirmaría por enésima vez la validez del modelo tras una nueva visita:

¡Cuánta amabilidad en los Padres y Hermanos! iQué sencillez y amabilidad en las fervorosas conversaciones del Ilmo. Sr. Obispo! iCon cuánta confianza y amor veíamos acudir toda clase, edad y sexos de benga a este venerable anciano que, como buen Pastor y cariñoso Padre, a todos consuela y deja satisfechos! ¡Cuánto silencio, paz y concordia entre los Padres y Hermanos! ¿Y qué diré de aquellos ochenta niños que estaban en casa de los Padres, y cincuenta niñas que educaban las monjas en la suya? iCuán atentos y silenciosos se mostraban! Todo, en fin, edificaba en aquella casa. Fuimos al Mes de María, y todo cuanto había en aquella grandiosa iglesia me sugería ideas y pensamientos que me animaban a continuar en la dura tarea de catequizar, etc., a estos negritos ${ }^{19}$.

18 Expresión de humildad científica que, en realidad, se refiere a la costumbre, ampliamente practicada en las áreas de influencia misionera, de bautizar a los enfermos «sub conditione» o «in articulo mortis». También daba lugar a escenas edificantes, e incluso a algunas apariciones terminales de la Virgen a las que ya hemos aludido.

19 VILA, Isidre: s/t [carta de 20 de mayo de 1886], en Boletín Religioso de la Congregación de Misioneros Hijos del Inmaculado Corazón de María (Madrid), volumen 2, julio-diciembre de 1886, pp. 36-38. 
En definitiva, la Misión de Libreville dedicaba la mayor parte de sus esfuerzos a la conversión de los «benga», es decir de los «indígenas» de su propia área de influencia, con el objetivo de formarlos como católicos y productores útiles para la colonia. Para ello disponían de una escuela masculina y otra femenina, ambas con un internado que acogía a alumnos de la misma zona, atendido el segundo por religiosas. Y buscaba una cierta capacidad de autofinanciación, que lograba mediante el trabajo de los coadjutores y de los alumnos mayores y que justificaba la presencia de una finca de cultivos diversos como parte de la actividad de la Misión.

El P. Ramírez, recuperado y resarcido, aprovechaba el viaje de vuelta para visitar la cercana isla de Corisco, suelo español, con el fin de

sondear la disposición de ánimo en que se hallaban los bengas para recibir la Misión. (...) Entendido el objeto de su visita, manifestaron los isleños muy buenos deseos de recibir la Misión, si bien, como después se vio, iban mezclados con algo de egoísmo, el cual no dieron a entender por entonces ${ }^{20}$.

Reunido finalmente con su Superior General, sólo quedaba ajustar unas piezas que, al fin y al cabo, encajaban por completo con justeza y fidelidad:

Enterado el Rdmo. P. Prefecto del procedimiento que los beneméritos religiosos del Santo Espíritu e Inmaculado Corazón de María guardaban en la evangelización de los gaboneses, y persuadido de que uno de los puntos más interesantes y de mayor fruto era la instrucción de la juventud, según había tenido ocasión de presenciarlo en el hermoso plantel que los Padres citados tenían en su colonia, determinó ensayar este medio en Santa Isabel. A esto mismo impelía el estado tristísimo de la juventud de esta ciudad. iDios mío! iCuántos peligros! ¡Cuántos malos ejemplos, aun de aquéllos que debían corregirlos! En los bosques, en los caminos, en las calles y en sus mismas casas aprendían el mal; y se veía andar en las calles a muchos de ellos sirviendo de simples criadillos, pero sin la menor instrucción religiosa. Con lo cual determinaron nuestros misioneros abrir un colegio de internos y, para que mejor recibida fuese la idea y poder al propio tiempo proporcionar a la colonia operarios útiles para los oficios más perentorios, valiéndose de los Hermanos coadjutores abriéronse también talleres de sastrería, zapatería y carpintería. Dióse con esto un gran paso, porque al propio tiempo que se libraba a los jóvenes de muchos peligros, había ocasión de corregirles con más facilidad y de hacerles adquirir hábitos de trabajo, al que son muy refractarios ${ }^{21}$.

La Misión guineana no sería un remiendo, y el objetivo quedaba establecido para siempre: sacar a los jóvenes de los «espacios agresores», «los bosques, los caminos, las calles y sus mismas casas», y trasladarlos de forma munificiente a ese

20 Coll, Ermengol: Misión de Santa Isabel, edición de Jacint Creus y Ma Antònia Brunat, Vic, 1997 [circa 1908], p. 32.

21 Ibídem, p. 33-34. 
nuevo espacio, manifiestamente moderno, en que aprenderían a ser "operarios útiles para los oficios más perentorios», en lugar de servir de «simples criadillos».

\section{EN MUY POCO TIEMPO PODRÁS SER LIBRE \\ IN EXIGUO TEMPORE LIBER ERIS}

Una vocación es lo contrario de una carrera. Los dos Superiores claretianos habían realizado una larga travesía para apreciar con sus propios ojos algo deseado, y creían poder complacer en la realidad el encanto de su sueño. Prefirieron la carrera a la vocación; y tras el arribo de dos nuevas expediciones misioneras $^{22}$, dedicaron esfuerzos y ahíncos a asegurar la presencia de la religión en todo el territorio colonial conocido. La cronología frenética quedaba restablecida: en febrero de 1885 se creaba el colegio femenino de Santa Isabel y también la Misión de Banapá; en marzo, las Misiones del cabo de San Juan y de la isla de Corisco; en agosto, la de la isla de Annobón; en agosto de 1886, la del islote de Elobey; en enero de 1887, la Misión de Batete en Fernando Poo, así como la ampliación de la Casa central de Santa Isabel, que se volvería a producir en abril y mayo de 1889; en enero de 1888, la Misión de Concepción, en el actual Riaba; en noviembre de 1890, la Casa concepcionista de Corisco; en octubre de 1892, la Misión de Basilé; en julio de 1896, la de Musola; y en julio de 1898, la femenina de Basilé, en substitución de la capitalina. Una expansión presurosa en forma de áreas de influencia sucesivamente trianguladas: Fernando Poo estuario del Muni - Annobón, en el conjunto colonial; Santa Isabel - Batete - Concepción, en la isla; Cabo de San Juan - Corisco - Elobey, en el estuario del Muni; Santa Isabel - Banapá - Basilé, junto a la capital; San Carlos - Batete - Musola, en la bahía de Wesbe. La expansión dejaba fuera las zonas en litigio con Francia (y con el Vicariato Apostólico de las Dos Guineas), desistiendo, en consecuencia, del litoral del entorno de Bata, hasta el río Benito; y, naturalmente, del «interior continental», aún desconocido por los europeos. Resultante de una vocación primigenia, la rauda carrera de la extensión de las Misiones encubría apenas una apetencia política: la ocupación territorial efectiva del conjunto de los territorios coloniales. De ahí el resuelto amparo de la Administración del Estado, que iría favoreciendo no sólo la constitución de Misiones nuevas, sino de formas de actuación cada vez más costosas, y no sólo económicamente: de pie para defenderlas, de rodillas para venerarlas. Porque el precio, recordemos, era el monopolio de la acción civilizadora. Y si la expansión católica era el objetivo

22 La de 27 de enero de 1885 estaba formada por 19 claretianos y 5 religiosas concepcionistas, a los que sucesivamente se unirían 7 claretianos y 3 concepcionistas más en pequeñas expediciones intermedias. La de 7 de enero de 1887 constaba de 22 efectivos, todos ellos claretianos. El número de religiosos, en aquel momento, superaba los 60 efectivos, doblando sobradamente a los de la Misión de Sainte Marie. 
estratégico de la Administración para asegurar una presencia colonial efectiva, el de los claretianos era también diáfano: reproducirse en sus propios términos.

En lugar de abrir las ventanas de sus establecimientos a la noche ecuatorial para contagiarse de la oscuridad templada, resolvieron forjar esos nidos que los pájaros tejen con las cosas más disparatadas, anhelantes de sentirse «aislados» del exterior recelado: como la golondrina de mar proustiana, que lo construye en el calor de la tierra, al fondo de un subterráneo. Igual que acontece en tantas historias, nuestros misioneros iban a ser más inflexibles que su modelo francés, en que el «espacio redentor» ya se concebía con la severa ausencia de aperturas:

Instruits en une langue européenne, ces enfants, rentrés chez eux, oublient tout, langue et religion. De plus, ils sont incapables, ayant appris le catéchisme en français, de l'expliquer autour d'eux dans une langue indigène : c'est un fait d'expérience ${ }^{23}$.

Los niños, cuyo caudal de conocimientos sintetizaban la flamante lengua europea y la bisoñez de una nueva religión, no debían volver a ese «exterior recelado», ese «espacio agresor» donde «lo olvidarían todo».

El movimiento, como en el caso del viejo «rey» Moka, iría de la «caballerosidad» a la exigencia:

El indigente pueblo no dejaba de pedir mil cosas que no se podían dar. Eran una incesante molestia, tanto más pesada cuanto que eran mayores los deseos de contentarlos y mayor la falta de recursos, que lo imposibilitaban. En este tiempo empezó la escuela, se hizo un pequeño huerto, se abrió un pozo, se preparó un local para la Casa nueva, etc.»24; «No sé por qué en estas Misiones no somos más escrupulosos en el uso de la caña [aguardiente de caña] con los indígenas... No deja de tener bastantes inconvenientes el que, en la Misión, por fas o por nefas la tomen, y varios cojan borracheras» 25 ; "Acostumbrados aquellos indígenas mal, ahora se resisten a entrar en camino, y ningún Superior o Padre, si no da, es bueno. El querer hacer cristianos a fuerza de dar no produce buenos resultados. El negro no es agradecido, y el regalar sin ton ni son hace que él se crea hasta con derecho a que se le dé; si no... no rezará, etc., etc. ${ }^{26}$.

23 Le Roy, Mgr.: Conditions auxquelles la juridiction pourrait être accordée aux Pères de la Préfecture de Fernando Poo dans le Vicariat Apostolique du Gabon, documento inédito del Prefecto Apostólico sucesor de Mgr. Le Berre, de 22 de marzo de 1898. Archivo Central de los Padres del Santo Espíritu (ACSSP), Deux Guinées, Caja 168, Dossier B, II.

24 Historia de la Casa-Misión de Annobón, documento sin catalogar ni paginar. Archivo Claretiano de Malabo (APG.CMF).

25 Carta del P. Joaquim JuAnola al P. Josep Xifré, Superior General de la Congregación, de 18 de febrero de 1898. AG.CMF, F, N, 9, 1. En otras cartas del mismo autor se alude a la venta de escopetas y de munición como forma de atracción de los bubis hacia la Misión. Vid. Epistolario del P. Joaquim Juanola, CMF, edición de Jacint CREUS, Vic, CEIBA, 2003, 78 págs.

26 Ibídem. 
El paso de un estadio a otro tendrá que ver con dos progresiones paralelas: una mayor agresividad claretiana hacia el entorno, que sólo podrá aparecer cuando el «espacio redentor» funcione con autonomía; y una creciente hostilidad del entorno africano hacia la Misión, porque esa hipotética autonomía incluía a hijos e hijas de aquellos «indígenas» abandonados a la ira. Evidentemente, la literatura misionera ensalzará siempre a una sola de las partes:

Por otra parte, esta Misión siempre se ha distinguido por su modestia y pobreza; y, si me es permitida la expresión, era aquella Casa como un facsímile de la vivienda de Nazaret. Hubo época, en tiempo de la fundación, en que llegaron nuestros Padres a alimentarse con la insulsa, indigente y tan difícil alimento de la yuca, que es un tubérculo semejante a un nabo de corteza leñosa y cuya carne es casi pura fécula ${ }^{27}$.

El lector debe tener en cuenta este movimiento sincopado, «en forma de espejo», que refleja de forma lóbrega la parte contraria del «otro» discordante. El inicio la maniobra corresponde a la elección de la ubicación de cada nueva Misión y a sus primeros compases:

A falta de edificio para escuela la comenzaron al aire libre. Colgaron de una palmera un cartel y comenzaron a enseñar a aquella multitud de rapazuelos casi desnudos las primeras letras. Algunos de ellos mostraban una aptitud no despreciable, por lo cual nuestros misioneros se iban aficionando a enseñar y los niños a aprender. No faltaban, por supuesto, premios de asistencia y de aplicación, consistentes en confites y golosinas, lo cual hacía que la escuela fuera siempre muy concurrida; y como por una parte no hacían falta bancos ni sillas para aquellos pequeñuelos, ni el local resultaba nunca pequeño, no asustaba a los Padres misioneros la mucha concurrencia ${ }^{28}$.

Es un estado accidental y pasajero, sujeto a una consigna provicera:

Le ruego con igual ardor que, sin temores ni respetos o pusilanimidades, reúnan, vistan, alimenten y admitan en nuestras casas y escuelas todos los niños posibles; y que se haga cuanto se pueda, dentro de la decencia, en orden al vestido de las niñas y mujeres; a todos los cuales deseamos que se trate con la cordura, educación y amabilidad que prescribe la ley de Jesucristo29.

El momento de la ruptura es cuando los internados se convierten «sin temores ni respetos o pusilanimidades» en el centro real de la Misión; y la consecución de niños, una especie de obsesión agraviante de la actividad misionera:

\footnotetext{
27 Misión de Cabo San Juan. AG.CMF, F, N, 8, 7, documento sin paginar.

28 Coll, Ermengol: Misión de María Cristina, op. cit., p. 25.

29 XIFRÉ, Josep: "Carta circular a los misioneros del golfo de Guinea», en Boletín Religioso de la Congregación de Misioneros Hijos del Inmaculado Corazón de María (Madrid), volumen 1, noviembre de 1885 - junio de 1886, p. 339-343.
} 
Tenemos ya nueve niños bubis internos y con muchos deseos de recibir el bautismo y de no volver jamás a sus casas. Todos menos dos se han escapado de sus casas por los grandes deseos que tienen de estar con nosotros. Es ley entre los bubis que el hijo se puede marchar de sus padres sin que puedan reclamarlo» 30 ; «Contribuía algo al aumento [el jefe bubi] Ullem, quien, porque recibía más regalos de la Misión que otros, quería el P. Pinosa que contribuyera más que los otros a su desarrollo, Así, sucedía a veces que, durante algunas temporadas, se le mostraba el Padre serio y ceñudo, a fin de que le trajese algún niño a la Misión; pues bastaba que nuestro hombre se hubiera pasivamente, para que algunos escaparan del bosque a la Misión ${ }^{31}$.

«Escaparse a la Misión» es, pues, la expresión exacta que debemos aplicar al reclutamiento de alumnos; la «ley de los bubis», una mayoría de edad que no existe más que en la cultura occidental, el pretexto para que la Misión se convirtiera en «refugio» de los evadidos. Y una sospecha: porque, en la medida en que podemos conceder veracidad al testimonio misionero, la incorporación de niños a los internados exigía la previa ruptura de éstos con los suyos. Una especie de segunda oportunidad vital que precisaba — o agudizaba - la desarticulación e impedía siquiera una bendición contrita.

Consiguientemente, los estadios sucesivos excluían ya cualquier reciprocidad con el exterior y desarrollaban el modelo, lo perfeccionaban, con la intención de hacer innecesario el trato con aquellos «espacios agresores» de los cuales los niños «habían sido salvados». Al mismo tiempo, y con la concomitancia de la Administración, cada Misión se dotaba de nuevos edificios y de recursos nuevos para completar una «desconexión» que se pretendía íntegra:

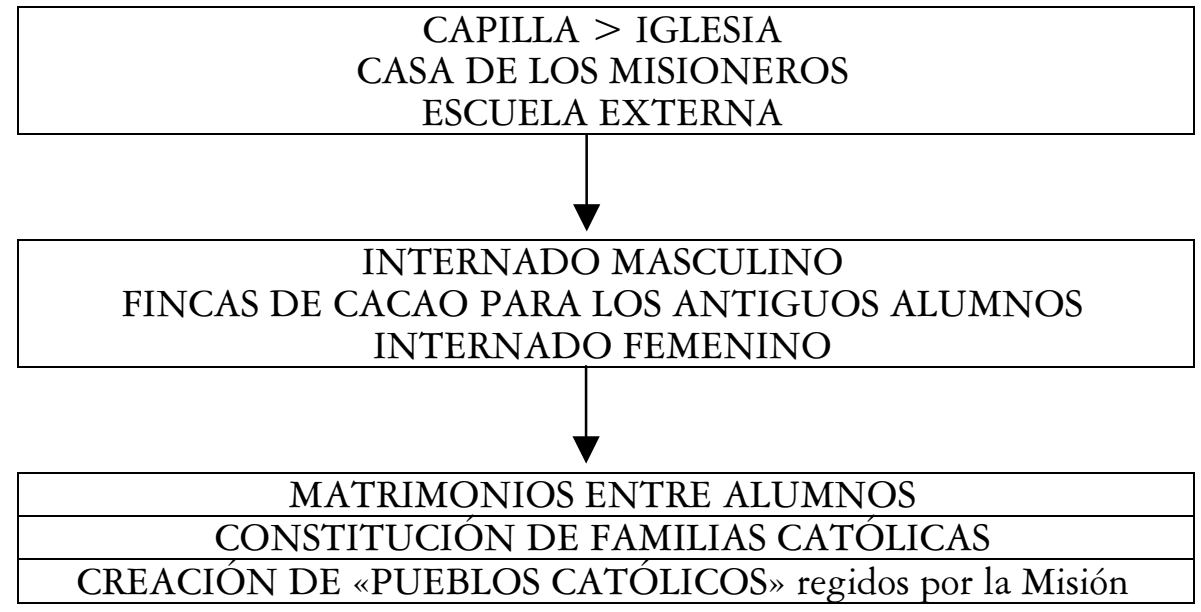

30 Carta del P. Jaume Pinosa, Superior de la Misión de Batete, al P. Climent SerRat, subdirector de la Congregación, de 1 de octubre de 1887. AG.CMF, F, P, 7, 6.

31 Coll, Ermengol: Misión de María Cristina, op. cit., p. 28. 
Si el momento de la ruptura — personal, social — viene representado por la creación de internados, el de la creatividad sin posible retorno, el de la originalidad del modelo claretiano, su separación del modelo gabonés, se da cuando los misioneros comprenden que los alumnos retenidos pueden imaginar su propio futuro al margen de sus estructuras familiares. Cuando la Misión se da cuenta de que puede sustituir a la familia en sus funciones de protección y en su obligación de procurar un medio y un modelo de vida para ellos. En ese momento, el objetivo de que los niños lleguen a ser «operarios útiles para los oficios más perentorios» se torna inútil:

[El oficial inspector de colonización] es de parecer que, respecto a los jóvenes de la Misión, la Misión debiera procurar recabar de Madrid la concesión a la Misión misma, ya de Concepción, ya de San Carlos, unas 100 ó 200 hectáreas o más, y luego entregarlas a los jóvenes en pequeñas parcelas con la obligación de una módica compensación; y sobre todo de que, si no se portan bien, serán privados de la finca32.

La conversión de los jóvenes en productores de cacao significaba también su inserción en un sistema de mercado que, siempre a través de los misioneros, les aportaba ventajas económicas y acceso a bienes de consumo. La sedición podía viajar del sueño visionario a la realidad deseada:

Esta Misión lleva seis años desde su fundación a esta parte, y en ellos, a Dios gracias, se ha podido fundar un colegio para niños de ambos sexos que han de vivir, con el favor de Dios, perpetuamente al lado y bajo la protección de la Misión, a pesar de que ponen los padres y amos de los muchachos todos los obstáculos que pueden para impedirles el venirse con nosotros, lo que logramos, después de Dios nuestro Señor, por medio de regalitos, principalmente ropas, adornos, tabaco, etc. Con los nueve matrimonios que hay actualmente tenemos los fundamentos de un pueblo cristiano y piadoso, porque a esto le ayudará el no haber en ésta ninguna familia de blancos, que, generalmente, no acostumbran a venir por estas tierras los que dan buenos ejemplos ${ }^{33}$.

Los siguientes estadios verían a alumnos de los claretianos y a alumnas de las concepcionistas casarse entre ellos («Él dice que si los niños y niñas van a la Misión, luego uno quiere a otra y el Padre los casa y pierdes») para formar familias católicas que serían el germen de pueblos católicos regidos por luengas barbas, cabezas sesudas. Los claretianos, en definitiva, «gobernarían» los «espacios redentores» que habían creado, someterían las normas sociales a sus propias convicciones morales y políticas; e impartirían justicia, «su» justicia, en

32 Carta del P. Joaquim Juanola al P. Martí Alsina, Superior General, de 28 de enero de 1901. AG.CMF, F, P, 6, 9.

33 Bolados, Alfredo: s/t [carta al Vicario Apostólico de Tarapacá], en El Iris de Paz, o sea El Inmaculado Corazón de María (Madrid), 1894, p. 22-23. 
nombre de una Administración escandalosamente ausente. No más en la tierra. Nada más intenso, nada más profundo, nada más rabiosamente agudo. Nada superior: la cruz dominaba en una parte de Guinea y convertiría a sus usuarios en civilizados primero, en ciudadanos después, en privilegiados siempre.

La otra parte nunca entendería el proceso, pero jamás renunciaría a sus niños, a sus estructuras familiares: «iSi al menos dejaran venir libres a los niños y niñas!!! Pero no hay medio...», se lamentaba el P. Juanola en su tercera visita a Moka. Y la volatilidad del conjunto del modelo se correspondía con la capacidad de decisión que los propios misioneros habían concedido a la voluntad de unos internos que

recién salidos del bosque no han llevado ni saben llevar vestido limpio, ni les importa que se rasgue o esté entero, a quienes se ha de dar de comer, se ha de instruir en todo, y de quienes, para adelante, no puede $\mathrm{Vd}$. esperar apenas una señal de agradecimiento; sumamente perezosos para el trabajo, al cual no van, sobre todo al principio, sino a pura fuerza; no los puede Vd. castigar ni reñir demasiado, porque se escaparán fácilmente ${ }^{34}$.

Los claretianos siempre fueron conscientes de la delicada fragilidad de su situación y de la postura amarga de las familias de sus alumnos, atenuada sólo por la contundencia policial:

Sus padres, como no aprecian civilización ni instrucción porque no conocen sus ventajas, los quieren para emplearlos en el cultivo de ñames y tenerlos en su compañía. Si se diera el caso de que los bubis se llevaran a sus hijos, tan pronto como podrían éstos escapar de sus padres volverían a la Misión; pero conociendo aquéllos que el Gobierno estaba contra nosotros y les daba a ellos la razón, serían capaces de incendiarnos las Casas o hacernos algún otro perjuicio para arrancarnos los niños; y entonces perdemos el fruto de estos años y todas las esperanzas que teníamos, pues las cifrábamos todas en estos chicos, que por cierto son buenos. Confío que no permitirá nuestra Madre Santísima que esto suceda ${ }^{35}$.

La diferencia con respecto a Europa radica, precisamente, en esos padres que «no aprecian civilización ni instrucción porque no conocen sus ventajas»; es decir, esos padres que, al contrario que nosotros, aún no habían aprendido su derecho a no abandonarse a la ira, a no macerar en lágrimas el corazón compungido, a exorcizar con su bendición apenas contrita una separación doliente que encubría su propia desarticulación. Padres que atacaban a unos misioneros desconcertados por una reacción tan inaudita:

Esto, que se supo algunos años más tarde, quedó entonces entre los bubis viejos, que se retrajeron de la Misión y para nada se fiaron del Superior. Éste, en

34 Carta del P. Ermengol Coll al P. José MATA, de 4 de noviembre de 1893. AG.CMF, F, N, 16, 1.

35 Carta del P. Ermengol Coll al P. Josep XIFRÉ de 12 de febrero de 1891. Ibídem. 
su celo, no recelaba de ellos ni creía que fuesen capaces de hacerle daño; pero, por la enfermedad rara de que murió, probablemente le propinaron veneno ${ }^{36}$.

La Misión en bubis es espinosísima, pues de nuestros trabajos recogemos calumnias, las cuales nos hacen no pequeño daño. Dicen que matamos los niños y que nos los comemos, que los cogemos para mandarlos a España y allí los matarán y harán mil diabluras con ellos. Tan horroroso es el miedo que les han infundido a los niños, que huyen de las sotanas como de una fiera; cuanto más se les llama más lejos se retiran. iDios tenga compasión de los infelices!, pues bien podemos decir no saben lo que se hacen [Lc, XXIII, 34]. Es muy grande el poder que tiene el demonio entre ellos; y como es nuestro capital enemigo, no es de extrañar nos haga cruda guerra haciéndoles refractarios a la Misión, pues continuamente le están consultando y haciéndole sacrificios para que les sea propicio en todas sus obras; y están persuadidos de su poder ilimitado, de modo que si un misionero enferma y tiene que ausentarse de la Misión, ya dicen que le castiga el demonio por ser su enemigo, etc. ${ }^{37}$.

El 15 por la mañana viene el Hermano Vilamasana de San Carlos con una carta del Padre Sala, diciendo que los bubis les están amenazando y quieren llevarse de la Misión a las mujeres y niños ${ }^{38}$.

Los niños eran buenos, también los que pretendían huir de sus padres obstinados, excusables quizás por sucumbir o incapaces de resistir a lo que podían obtener en los internados: al conocimiento de una flamante lengua europea y la bisoñez de una nueva religión se añadía ahora el usufructo de una finca de cacao, su venta asegurada a las compañías coloniales o peninsulares, el matrimonio sin dote con alguna compañera, la posesión de una casa... una vida casi de blancos que, sin embargo, no merecía el aprecio de los suyos:

De matrimonios los habrá, Dios mediante, en mayor número dentro de poco, a medida que nuestros alumnos vayan creciendo en edad: pues hay varias muchachas que huyen de sus butukus para venirse a la Misión; por más que han de ir con cautela en no alejarse mucho de ella, porque los bubis están de acecho esperando una ocasión oportuna para cogerlas y llevárselas otra vez a la infidelidad, como sucedió no ha muchos días, que armaron los bubis una emboscada y cogiendo a una se la llevaron, aunque después escapó otra vez a la Misión. Sin embargo, ahora no son los bubis tan atrevidos como antes, porque temen a la Misión y a los muchachos mayores, que tienen todos su arma de fuego en defensa propia ${ }^{39}$.

La separación no tenía ninguna posibilidad de retorno. Pero en esa ausencia de los niños, los padres africanos no veían gravitar su propio éxito.

36 Coll, Ermengol: Misión de María Cristina, op. cit., p. 32-33.

37 Carta del P. Luis SÁENZ, Superior de la Misión de Concepción, de 25 de octubre de 1890. AG.CMF, F, P, 6, 9.

38 Carta del P. Ermengol Coll al P. José MATA, de 20 de noviembre de 1893. AG.CMF, F, $\mathrm{N}, 16,1$.

39 Singla, Josep: s/t [carta desde la Misión de Batete, de 30 de octubre de 1892], en El Iris de Paz, o sea El Inmaculado Corazón de María (Madrid), 1893, p. 27-28. 


\section{POR ESTOS SERVICIOS, OTÓRGAME UNA DULCE RECOMPENSA}

PRO QUIBUS OFFICIIS PRETIUM MIHI DULCE REPENDE

Mientras en Guinea la cruz de los católicos fervientes abría sus brazos, enrojecidos con la sangre de un Dios, a los pies de Montmartre, en el boulevard Clichy, las bailarinas de cancán levantaban las piernas al aire, haciendo honor a su reputación, con una elasticidad que mostraba a los cuatro vientos, desde ese Moulin Rouge que atrajo a tantos pecadores, el triunfo de la ligereza, de la despreocupación, de la joie de vivre de los nuevos tiempos. El divin chabut parisino desafiaba a la fanfarria procesional de la cumbre de la loma desde ese pequeño cabaret del Pigalle fundado por otro catalán, Josep Oller, en 1889. Ambos persisten: el antro de perdición y el templo expiatorio.

Del mismo modo, los «espacios redentores» fraguados por los claretianos debían convivir con el modelo «laico» de Santa Isabel, que «se compone la mitad de toda la escoria de las sectas protestantes del continente occidental de África» ${ }^{40}$, con el «desenfreno» de los colonos y la terquedad de los «indígenas». Estandartes de la acción civilizadora hispánica, las Misiones cerraron el círculo muy pronto, gracias como siempre al apoyo administrativo, que en sucesivas leyes reguladoras del «trabajo indígena» y del «estatuto indígena» convirtieron a muchos de los alumnos de las Misiones en «emancipados», en «privilegiados»: no en relación a los europeos, naturalmente, sino en relación al resto de africanos, los desafectos, los excluidos, y, naturalmente, los inmigrados a la nueva colonia de producción, la enorme finca de cacao en que se había convertido Fernando Poo para deleite de nuestros desayunos y meriendas. Llama la atención la creación de un modelo de ciudadanía producido a base de sucesivas exclusiones, de exclusiones concéntricas, donde finalmente sólo quedaban dentro del sistema colonial los europeos y esos emancipados, mientras que la mayoría de la población debía permanecer o bien fuera, o bien en aledaños largamente subordinados por el sistema de explotación. La exclusión como norma, en el corazón — sagrado corazón - de esa África que siempre había practicado la inclusión como norma, también en violentas épocas de trata nada lejanas: inclusiones sucesivas, inclusiones concéntricas hacia cuyo centro todos podían converger.

La Historia amagó con acelerarse y llegó la mal llamada independencia: como ese «instante en que el enfermo, obligado a salir de viaje y que debe dormir en un hotel desconocido, que al despertarse de una crisis se alegra porque percibe bajo la puerta un rayo del día» ${ }^{41}$. Quizás el triunfo de la cruz había durado en exceso. No es el tema de mi análisis. Pero en esa Guinea de hoy, lacerada por nuevas infamias, la idea de la separación, de la exclusión como norma, parece consubstancial al ejercicio del poder. Un poder que también se pre-

40 Carta del P. Joaquín de Acosta, párroco de Santa Isabel, al Cardenal Prefecto de Propaganda Fide, de 5 de enero de 1879. ASCPF, Scritture riferite nei Congressi: Africa: Angola, Congo, Senegal, Isole dell'Oceano Atlantico, vol. 8, f. 628-630.

41 Proust, Marcel: À la recherche du temps perdu, París, Gallimard, 1987, I, p. 4. 
senta a los guineanos como una oportunidad posterior a la sedición. Anticuado ya en un mundo que proclama otros valores, pero que también será condescendiente con esa excepción instigada por todos porque a todos conviene. Un poder que funciona en forma de exclusiones sucesivas, concéntricas, en cuyo corazón encuentran derechos sólo los que abren sus brazos, regados con la sangre de un Dios grotesco, para dominar en su nombre a los otros, que ya no son los suyos. Ese Dios también es selectivo. Una parte de esta Historia de hoy empezó ayer, en una noche ecuatorial, la primera en que el tañido melancólico de una campana ahogó, en la templada oscuridad, el sollozo apenas perceptible de un niño añorado de dulzura, contenido durante el día ante aquellos extranjeros que lucían el aspecto anormal, excesivo, vergonzoso y meritorio de los solterones. 